\title{
Audiology
}

\section{Acquired sensorineural hearing loss in children: current research and therapeutic perspectives}

\author{
Sordità infantile acquisita: stato dell'arte della ricerca e prospettive terapeutiche \\ M. RALLI', R. ROLESI ${ }^{2}$, R. ANZIVINO², R. TURCHETTA ${ }^{3}$, A.R. FETONI ${ }^{2}$ \\ ${ }^{1}$ Department of Oral and Maxillofacial Sciences, Sapienza University of Rome, Italy; ${ }^{2}$ Department of Otolaryngology, \\ Catholic University of Sacred Heart, Rome, Italy; ${ }^{3}$ Department of Sense Organs, Sapienza University of Rome, Italy
}

\begin{abstract}
SUMMARY
The knowledge of mechanisms responsible for acquired sensorineural hearing loss in children, such as viral and bacterial infections, noise exposure, aminoglycoside and cisplatin ototoxicity, is increasing and progressively changing the clinical management of affected patients. Viral infections are by far the most relevant cause of acquired hearing loss, followed by aminoglycoside and platinum derivative ototoxicity; moreover, cochlear damage induced by noise overexposure, mainly in adolescents, is an emerging topic. Pharmacological approaches are still challenging to develop a truly effective cochlear protection; however, the use of steroids, antioxidants, antiviral drugs and other small molecules is encouraging for clinical practice. Most of evidence on the effectiveness of antioxidants is still limited to experimental models, while the use of corticosteroids and antiviral drugs has a wide correspondence in literature but with controversial safety. Future therapeutic perspectives include innovative strategies to transport drugs into the cochlea, such as molecules incorporated in nanoparticles that can be delivered to a specific target. Innovative approaches also include the gene therapy designed to compensate for abnormal genes or to make proteins by introducing genetic material into cells; finally, regenerative medicine (including stem cell approaches) may play a central role in the upcoming years in hearing preservation and restoration even if its role in the inner ear is still debated.
\end{abstract}

KEY WORDS: Acquired hearing loss $\bullet$ Pediatric otolaryngology $\bullet$ Genetic diagnosis $\bullet$ Cochlear implant

\section{RIASSUNTO}

La conoscenza dei meccanismi fisiopatologici delle condizioni responsabili dell'ipoacusia acquisita nei bambini, tra cui le infezioni virali e batteriche, l'esposizione al rumore, l'ototossicità da chemioterapici ed antibiotici aminoglicosidici, è in costante aumento e sta portando ad un progressivo cambiamento della gestione diagnostica e clinica del bambino ipoacusico. Le infezioni virali rappresentano la causa più frequente di sordità infantile acquisita, seguita dalla tossicità di antibiotici e chemioterapici; mentre l'esposizione al rumore, soprattutto negli adolescenti, rappresenta un fattore emergente. Le terapie farmacologiche protettive attualmente in uso includono steroidi, antiossidanti, antivirali; l'efficacia degli antiossidanti è ancora in fase di conferma clinica anche se vi sono significative evidenze sperimentali, mentre i farmaci steroidei ed antivirali sono certamente validi seppur la loro tossicità sistemica rappresenti ancora un problema non chiarito per i quali la somministrazione locale potrebbe rappresentare una possibile evoluzione. Le prospettive di ricerca future includono l'uso di nanoparticelle per veicolare molecole direttamente nel sito di danno; inoltre, la terapia genica con l'inserimento di materiale genetico all'interno delle cellule per la cura di condizioni da alterazione del patrimonio genetico con la produzione di proteine normali, potrebbe svolgere un ruolo rilevante nella cura e soprattutto nella prevenzione delle sordità acquisite; infine, la terapia rigenerativa e l'impianto delle cellule staminali, nonostante il loro ruolo nell'orecchio interno sia ancora dibattuto, per le notevole limitazioni del loro impiego, potrebbe trovare un ruolo nei processi riparativi più che nella differenziazione in cellule sensoriali.

PAROLE CHIAVE: Ipoacusie acquisite $\bullet$ Otorinolaringoiatria pediatrica $\bullet$ Diagnosi genetica $\bullet$ Impianto cocleare

Acta Otorhinolaryngol Ital 2017;37:500-508

\section{Introduction}

Advances in the development of diagnostic tools, neuroimaging techniques and molecular biology are rapidly changing the landscape of management in children affected by sensorineural hearing loss (SNHL) ${ }^{1}$; new cases of idiopathic hearing loss (HL) are significantly decreasing thanks to the introduction of diagnostic and therapeutic tools that go well beyond the traditional audiological examination and contribute to more accurate diagnosis and selective therapeutic approaches ${ }^{2}$. In the past, treatment of SNHL in children was performed exclusively with the use of hearing aids; in recent years, cochlear implants have radically changed the prognosis of deafness, and now play a central role in treatment of SNHL ${ }^{3}$.

The better understanding of the mechanisms involved in the acquired HL in children, such as viral and bacterial infections, noise exposure, aminoglycoside and cisplatin ototoxicity, gives way to innovative therapeutic approaches. It is becoming evident that oxidative stress is a final common endpoint for complex converging events, some genetically determined and some triggered by different stressors. These 
pathways of oxidative stress are the major causes of most types of SNHL, including hereditary drug-induced- and noise-induced $\mathrm{HL}^{4-7}$. At the same time, advances in molecular analysis and identification of new genetic alterations play a significant role in the improvement of aetiological classification ${ }^{89}$ and identification of different sensitivity to exogenous factors of specific genotypes and how they influence susceptibility to ototoxicity in children exposed to chemotherapeutic agents and antibiotics ${ }^{10-14}$.

Therapeutic approaches targeting the mechanism of cochlear damage are challenging, while hearing research is focusing on new strategies for treatment including the regeneration of neural epithelium and ganglion neurons through gene therapy, implantation of stem cells, and reactivation of the processes of cell differentiation ${ }^{15}$. In this paper, current pharmacological approaches will be reviewed.

\section{Current pharmacological approaches}

\section{Corticosteroids}

Cochlear inflammation in children has been observed in several pathophysiological conditions, such as electrode insertion during cochlear implant surgery, bacterial meningitis, labyrinthitis, otitis media, cisplatin treatment and autoimmune diseases ${ }^{16}$. TNF-alpha is a key pro-inflammatory and pro-apoptotic molecule in the cochlea, released both by fibroblasts in the spiral ligament and by outer hair cells and supporting cells in response to stress factors ${ }^{17}$. As seen in conditions such as HL following meningitis, inflammatory mechanisms can induce damage of the spiral ligament, death of hair cells, ossification of the cochlea and disruption of cochlear homeostasis ${ }^{18}$. On this basis, it is well known that systemic administration of steroids, such as dexamethasone, methylprednisolone and triamcinolone, is the most common clinical approach for cochlear inflammation in children. This approach is established on the empirical data and experimental observations of anti-inflammatory and immune suppressive activity of these molecules in the cochlea ${ }^{19}{ }^{20}$. However, the serious side effects of systemic administration can be avoided by local intratympanic administration or intracochlear application of polymers through the round window or by a micro-osmotic pump 2122 .

As previously described, protection from electrode insertion trauma in cochlear implantation represents a common condition in which steroid therapy is used ${ }^{23}$. Damage can be immediate or delayed, due to elevated noise and vibrations during surgery, insertion of the array, or activation of immunological and inflammatory mechanisms ${ }^{24}$. Prolonged treatment with steroids seems prevent both early and late damage ${ }^{25}$. These observations support the clinical use of dexamethasone administered through an array to guarantee the preservation of residual hearing, an important target in cochlear implant surgery. Experimental observations show that dexamethasone administered through a cochleostomy before implantation reduces signs of inflammation and improves the density of ganglion neurons; in addition, the availability of the drug increases from $2 \%$ to $20 \%$ if the infusion was performed 1 hour to 30 minutes before surgery ${ }^{26}$. An electrode (Nucleus 24 Contour, by Cochlear ${ }^{\circledR}$ ) having a built-in channel for the administration of steroids has been proposed ${ }^{27}$, and the reduction of electrode impedance values in patients treated with triamcinolone has been shown ${ }^{28} 29$. However, it is questionable whether a single application of steroids can interfere with a mechanism of continued damage and if the application of topical steroids may favour chronic problems such as infections. In a recent study in an animal model, dexamethasone (4 mg/ml) was parenterally delivered via a mini-osmotic pump for either 3 or 7 days; the delayed administration was more effective in preserving hearing than a 3-day delivery ${ }^{30}$.

A major use for steroids in children is treatment, in addition to antibiotic therapy, of bacterial meningitis. Community-acquired bacterial meningitis continues to be a heavy toll even in developed countries, despite the implementation of childhood vaccination programs and effective antimicrobial agents. The most common aetiological agents are Streptococcus pneumoniae and Neisseria meningitidis. Today about two-thirds of cases in Europe and United States are pneumococcal meningitis, and despite advances in medical care mortality is about $15-30 \%$ with neurological sequelae, including HL, occurring in about 30-50\% of surviving patients. It is known that bacteria cause the release of pro-inflammatory factors, breakdown of the blood-labyrinth barrier and loss of ganglion neurons which lead to fibrosis and ossification of the cochlear turns. A recent experimental study demonstrated that administration of betamethasone in a model of pneumococcal meningitis could reduce SNHL and loss of ganglion neurons ${ }^{31}$. However, in humans, a large series of studies involving nearly 600 cases in a population from Malawi did not support the effectiveness of treatment with dexamethasone ${ }^{32}$. In 2010, an epidemiological Cochrane analysis concluded that the effectiveness of an adjuvant treatment with steroids in children in developing countries is quite dissimilar ${ }^{33}$. A more recent Cochrane review examined the effect of adjuvant corticosteroid therapy versus placebo on mortality, HL and neurological sequelae in people, providing evidence that corticosteroids significantly reduced HL and neurological sequelae, but not overall mortality. Surprisingly, corticosteroids reduced severe HL in children with Haemophilus influenzae meningitis ${ }^{34}$.

Over 30 years ago glycerol, a diuretic and hyperosmotic agent, was used to reduce the HL sequelae of Haemophilus meningitis ${ }^{35}$. These results were corroborated by another study conducted in Finland, demonstrating equal efficacy of glycerol and dexamethasone ${ }^{36}$. On the contrary, a recent study showed that both intravenous administration of dexamethasone and oral administration of glycerol (or the combination of the two) could not prevent HL, suggesting 
that the children's general conditions and age are effective predictors for appearance of HL sequelae ${ }^{37}$. Despite the extensive use of steroids in treatments of conditions including ischaemia, viral infection and reactivation and microtrauma, better knowledge on the immuno-system of inner ear and the mechanism of immuno-mediated inner ear disease are still under needed, and therefore the precise mechanism of corticosteroids remains unclear. The inner ear was considered to be "immune-privileged" and to exclude all immunocompetent cells except in the endolymphatic sac; however, recent studies have demonstrated the presence of immunoreactive cells placed in other parts of the cochlea, mainly macrophages residing in the spiral ligament and spiral limbus. Recent advances in inner ear immunology are promising for a more rational and effective use of steroids in inner ear diseases.

\section{Antioxidants}

Recently, many antioxidant-based protocols have been introduced for multiorgan dysfunction in newborns who need intensive care, including hypoxia and reperfusion damage, sepsis and ototoxic drug administration. Newborn-preterm infants are susceptible to oxidative damage because of the immature antioxidant system and an environment much richer in oxygen; in addition, the preterm infant has increased susceptibility to infection and inflammation, which increases oxidative stress. In clinical practice, early markers of oxidative stress indicate that prenatal or peri-natal prophylactic use of antioxidants could help to prevent or at least reduce oxidative stress related diseases in newborns. Several protocols with lutein, melatonin, oxygen and magnesium and calcium channel blockers such as flunarizine have been introduced. Lutein administration in newborns, at 12 and 36 hours after birth, increases the levels of physiological antioxidant activity decreasing total hydroperoxides ${ }^{38}$. Hypothermia, a phenomenon which notoriously slows oxidative metabolism, has been proposed for prevention and treatment of hypoxic-ischaemic encephalopathy ${ }^{39}$. Interestingly, bilirubin showed a protective effect against oxidative stress at low levels, but was severely toxic at higher levels. We demonstrate that a polyphenol, ferulic acid, in a noise induced damage model, upregulates the expression of the haemeoxygenase 1 (HO-1) gene (Fig. 1), which is a phase two endogenous antioxidant enzyme with the ability to: (i) degrade haeme, which in the presence of ROS generates lipid peroxidation, (ii) produce biliverdin, which is the precursor of bilirubin with antioxidant properties ${ }^{40}$. Numerous studies have documented that continuous noise exposure in infants in newborn ICUs induces cochlear damage that can be incremented by the synergic effects of other stressors including hypoxia/reperfusion and aminoglycoside treatment. Paediatricians are encouraged to monitor sound in the newborn ICU and within incubators, and a noise levels $>45 \mathrm{~dB}$ should be avoided. Furthermore,

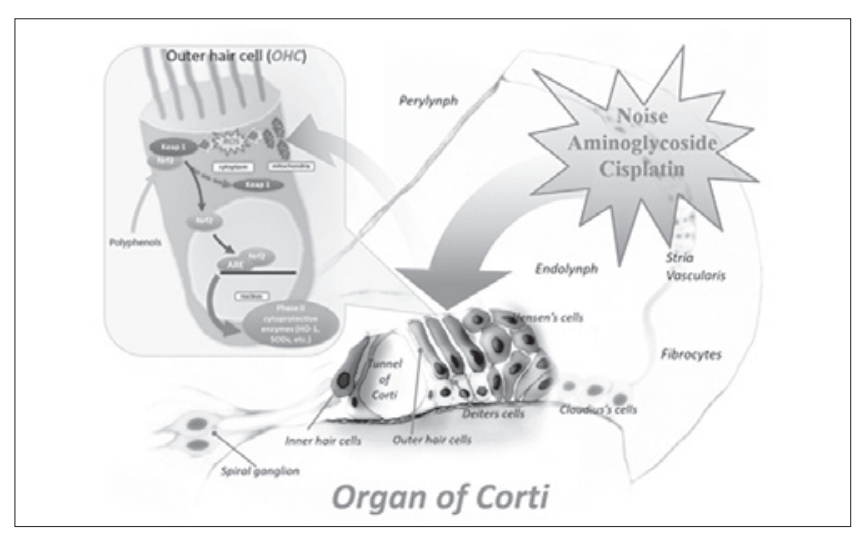

Fig. 1. Polyphenols can activate the Nrf-2/HO-1 pathway. We have demonstrated that many polyphenols (ferulic acid, curcumin) can potentiate endogenous antioxidant defenses both in outer hair cells and spiral ganglion neurons, promoting inactivation of the Nrf2-Keap1 complex. As a consequence, the enhancement of Nrf-2 nuclear translocation appears to upregulate the expression of many Phase-II cytoprotective enzymes (H0-1, SODs).

an estimated $12.5 \%$ of teenagers and adolescents aged 6-19 years have suffered permanent hearing damage from excessive exposure to recreational noise. Thus, strategies for hearing prevention and protection are desirable. Unfortunately, even if several experimental studies have shown the beneficial effects of antioxidant supplementation, limited results have been reported in clinical studies. Experimentally, the effectiveness of coenzyme Q10 and N-acetylcysteine has been extensively demonstrated. In a recent paper, Fetoni et al. demonstrated that a soluble formulation of CoQ10, called Q-ter, significantly reduces mitochondrial damage, lipid peroxidation and oxidative damage of cellular proteins induced by oxidative stress and decreases signs of apoptosis ${ }^{41}$; these data were confirmed by the same authors in which they also evaluated systemic versus transtympanic modality ${ }^{42} 43$. In addition, in a pilot prospective study, randomised and double-blinded, significant hearing protection was shown in a group of young volunteers that received Qter $200 \mathrm{mg}$ once a day for 7 days before exposure to white noise at $90 \mathrm{~dB}$ HL for 15 minutes ${ }^{44}$.

$\mathrm{N}$-acetylcysteine (NAC) is a derivative of cysteine that acts as an augmenter of the antioxidant glutathione reserves in the body. NAC is used as a mucolytic agent and in the treatment of diseases and conditions caused by oxidative stress, such as paracetamol toxicity and nephropathy induced by contrast agents ${ }^{45}$. In vivo studies have shown that NAC works as a scavenger of ROS, but its main antioxidant activity derives from being a precursor of cysteine, itself a precursor in the formation of glutathione. In addition, NAC protects against mitochondrial damage and reduces glutamate excitotoxicity both in outer hair cells and dendrites of afferent neurons. NAC is one of the few molecules tested in clinical trials involving children affected by acoustic trauma. In a randomised placebo-controlled double-blind study including a population of adolescents exposed to loud music, oral NAC 
(900 mg single dose) or placebo were given 1 hour before exposure to loud music. This study did not demonstrate a significant difference on the temporary threshold shift in hearing between the treated and placebo groups ${ }^{46}$.

Sodium salicylate is a potent antioxidant and anti-inflammatory drug with several effects on hearing function ${ }^{47}$. Salicylate hydroxyl groups destroy free radicals and promote translocation of the anti-apoptotic transcription factor NF$\mathrm{kB}$, preventing $\mathrm{HL}$ and cochlear damage especially when induced by aminoglycosides ${ }^{48}$ and cisplatin ${ }^{49}$. In a doubleblind controlled study involving patients treated with gentamicin for acute infections, aspirin at a dose of $3 \mathrm{~g} /$ day for 14 days showed a significant level of hearing protection compared with placebo ${ }^{50}$. However, long term treatment with salicylate has been reported to impair auditory neural activity ${ }^{51}$ and to induce tinnitus and $\mathrm{HL}^{5253}$. Antioxidants represent the most rational and safe approach for treatment of SNHL, although more data from clinical trials is needed for better knowledge of doses and timing of treatment.

\section{Protective agents against cisplatin-induced ototoxicity} Platinum compounds form the mainstay of currently used chemotherapeutic regimens for several malignancies in paediatric patients, such as neuroblastoma, germ-cells tumours, osteosarcomas, hepatoblastomas, brain tumours and relapsed and refractory lymphomas. Debilitating dose dependent side effects include nephrotoxicity, myelosuppression, neurotoxicity and HL. Although deafness is not a life-threatening condition and its degree is highly variable, HL causes communicative disorders in affected children that can result in a poorer quality of life. Thus, the development of effective strategies with protective molecules acting on the side effects without affecting or decreasing antitumour activity is recommended.

Several studies have demonstrated the effectiveness of sodium thiosulphate (STS) protection against cisplatin cytotoxicity ${ }^{5455}$. This molecule acts through its thiolic groups as a chelator of cisplatin, forming an inactive complex that prevents the absorption of cisplatin into the cell; unfortunately, differently from animal study results, the drug has been reported to reduce the effectiveness of systemic cisplatin therapy ${ }^{56}$. However, it has been shown that treatment with a delayed high dose of intravenous STS in children with malignant brain tumours a few hours after administration of carboplatin results in hearing protection without affecting the antineoplastic effect of cisplatin through alteration of the blood-brain barrier system ${ }^{57}$.

WR1065, the active metabolite of amifostine, has shown remarkable radio- and chemoprotective effects both in vitro and in vivo ${ }^{58}$. The conversion of amifostine to WR1065 is catalysed by alkaline phosphatase and depends on the presence of alkaline $\mathrm{pH}$. Differences in the concentration of alkaline phosphatase of normal versus cancer tissues can result in greater conversion of amifostine in normal tissues, providing relatively selective cytoprotection. The timing of the drug administration is an important factor for its protective efficacy and only limited pharmacokinetic data are available for children ${ }^{5960}$. Data from literature are often contradictory and several clinical reports focus on the peripheral neurotoxicity without studying HL.

Other protective drugs have been experimented in animal and human studies during the past few years; these include alpha-lipoic acid ${ }^{61}$, trichostatin A ${ }^{62}$, oxytocin ${ }^{63}$, resveratol ${ }^{64}$, hesperetin ${ }^{65}$ and lutein ${ }^{66}$. However, data are preliminary and have not been confirmed. From a critical reading of the literature, a lack of knowledge of the pharmacokinetic mechanisms, particularly in children, and a lack of data on dosage and ways of administration appear to be the main obstacles. Interestingly, attention has been more recently focused on the opportunity of molecular targeted approaches for cancer prevention and therapy and the use of adjuvant chemotherapeutics to overcome the limitations of cisplatin. Owing to their safe use, some polyphenols, such as curcumin, might modulate important pathways or molecular targets in cancers. We evaluated curcumin as an adjuvant molecule to cisplatin, demonstrating that curcumin attenuated all stages of tumour progression (survival, proliferation) and, by targeting pSTAT3 and Nrf-2 signalling pathways, provided chemosensitisation to cisplatin in vitro and protection from its ototoxic adverse effects in vivo. In the perspective of a personalised approach of cancer therapy, the beneficial effects of curcumin as an adjuvant agent to cisplatin offer strong preliminary data for clinical studies in humans ${ }^{67}$. Innovative approaches modulating the chemoresistence to cisplatin and acting in the prevention of its side effects is challenging for the future of antineoplastic therapy, especially in children who are more sensitive than adults to adverse effects such as ototoxicity.

\section{Antiviral therapy for CMV infection}

CMV is also a major cause of morbidity and occasional mortality in newborn infants. In recent years, it has become evident that CMV is the most important cause of congenital infection in the developed world, and that it frequently leads to mental retardation and developmental disability including HL and neuro-developmental delay. The incidence of congenital CMV infection ranges from $0.5 \%$ to $2 \%$ of all live births. Maternal CMV seroprevalence varies widely, ranging from $45 \%$ to $100 \%$, with higher prevalence and earlier CMV acquisition associated with lower socioeconomic status. Transmission can occur in mothers with no evidence of CMV immunity (primary infection) and in women with preexisting antibodies either by reactivation of previous maternal infection or by acquisition of a different viral strain during pregnancy. Primary maternal CMV infection during pregnancy is associated with a greater risk of in utero transmission, although about two-thirds of infants with congenital CMV infection are born from mothers with preexisting antibodies against CMV. Among congenitally CMV infected infants, 
approximately 10-15\% are symptomatic at birth. Clinical manifestations range from mild and transient symptoms to severe multi-system dysfunction including intrauterine growth restriction, petechiae, jaundice, hepatosplenomegaly, microcephaly, chorioretinitis and SNHL, which represents the most common non-genetic cause of SNHL. It has been estimated that HL occurs in nearly $50 \%$ of infants with symptomatic congenital CMV infection, while $7 \%$ of asymptomatically infected infants develop HL with delayed onset, or a progressive or fluctuating course ${ }^{68}$.

The measure of viral load, as determined by polymerase chain reaction (PCR) assay in blood, is a biomarker and a predictor of sequelae development. The effectiveness of control of viral infection during pregnancy and in the perinatal period is essential in decreasing early and late disorders and mortality. At present, there are no approved treatments during pregnancy to prevent or ameliorate the severity of foetal CMV infection. However, ongoing trials are studying treatment with hyperimmune globulin (HIG), pooled intravenous immunoglobulin and antiviral drugs to prevent mother-tochild transmission and ameliorate foetal sequelae. Currently, four antiviral drugs are available against CMV: ganciclovir, valganciclovir, foscarnet and cidofovir. Treatment with antiviral drugs cannot be recommended for use during pregnancy because of the limited evidence on their safety and efficacy ${ }^{69}$. Due to the increasing incidence of CMV infection, the need for antiviral therapy in infants and children is growing, and progresses in vaccine therapy will probably lead to the eradication of the infection ${ }^{70}$. Although there are limited data on the dosage, pharmacokinetics, safety and risk of adverse effects for some of these antiviral agents, the systemic administration of ganciclovir, due to its low oral availability, and its oral prodrug valganciclovir, have been extensively studied in the newborn ${ }^{71}$. Among adverse effects, it is important to highlight renal toxicity, which is irreversible for cidofovir and foscarnet, and neutropenia, more frequently associated with ganciclovir and valganciclovir. In addition, these drugs have other potentially serious toxic effects such as carcinogenicity, teratogenicity and azoospermia and deposition in bone or teeth (foscarnet) that may have significant implications when used in children ${ }^{72}$.

For these reasons, antiviral treatment should be reserved to severe cases. The most common treatment is intravenous ganciclovir (12 mg/kg/d in 2 doses), whereas oral administration of valganciclovir ( $32 \mathrm{mg} / \mathrm{kg} / \mathrm{d}$ in 2 doses) could be an alternative in some cases ${ }^{73}$. However, there is a lack of clinical experience in the post-natal period; there is little evidence of efficacy and pharmacokinetic studies are lacking in premature infants ${ }^{74}$. Duration of therapy is a controversial factor, as it should be continued for at least 2 to 6 weeks for intravenous therapy and up to 6 months for oral therapy; duration of treatment should be correlated with PCR monitoring ${ }^{75}$. Prophylaxis or treatment with acquired infection immunoglobulin in preterm infants showed no benefit to justify its use in all children. The treatment of children with early infection is effective in reducing HL in case of brain infection manifestations, but has been shown to be ineffective in asymptomatic infections. In a retrospective paper, it appears that about $90 \%$ of children maintain or enhance normal hearing after treatment, while the data on the efficacy of treatment in children with late diagnosis of $\mathrm{HL}$ are still limited ${ }^{76}$. Serological testing in at-risk pregnant women is recommended in prevention of conceptional infection, and identification in early pregnancy by serological testing may improve outcomes for CMV prevention ${ }^{69}$. Trials are needed to demonstrate the effectiveness of the use of antiviral molecules in less severe disease. The absence of guidelines is a major problem for management of CMV infection; however, the International Congenital Cytomegalovirus Recommendations Group has recently provided recommendations for prevention, diagnosis and treatment that are summarised in Figure $2{ }^{77}$.

\section{New perspectives in HL in children}

\section{Nanoparticles}

The use of nanoparticles has rapidly increased in hearing research in the past decade and probably represents the experimental approach that is closest to clinical applications for drug, peptide or gene therapy. In the inner ear, the most studied nanoparticles are biodegradable liposomes, nanocapsules and lipid micelles. The history of nanoparticles is quite recent and there are still many doubts concerning the type of nanoparticles, their stabilisation, their ability to reach and bind the target and their cochlear degradation. Recent experimental studies focused on the use of polyethyleneimine (PEI) and poly lactic-glycolic acid (PLGA); however, PEI was highly toxic and PLGA is still undergoing safety studies ${ }^{78}$. Lipid nanocapsules (LNCS), thanks to their lipoprotein-like structure with an oily core, show good distribution in the inner ear after application to the round window membrane ${ }^{79}$ and prolonged stability that permits close control on the dynamic release of the carried molecules. Interestingly, it has been demonstrated that lipid nanoparticles conjugated with a neurotrophic peptide focus selectively on the cells of the inner ear of mice ${ }^{80}$. However, the main concern about nanoparticles is their biocompatibility and intracochlear toxicity: in a recent study, it was shown that in vivo administration of lipid nanoparticles did not cause hearing damage or morphological changes in the inner ear ${ }^{81}$. In conclusion, nanoparticles can be equipped with targetability, immuno-transparency, although their application in clinical practice is still limited by possible side effects.

\section{Gene therapy}

Gene therapy has the goal to introduce a new or a regulatory gene in a target cell to replace or repair the defective gene ${ }^{82}$. Due to the risk of nucleic acid degradation related to the action of nucleases that recognise a foreign gene, gene therapy 


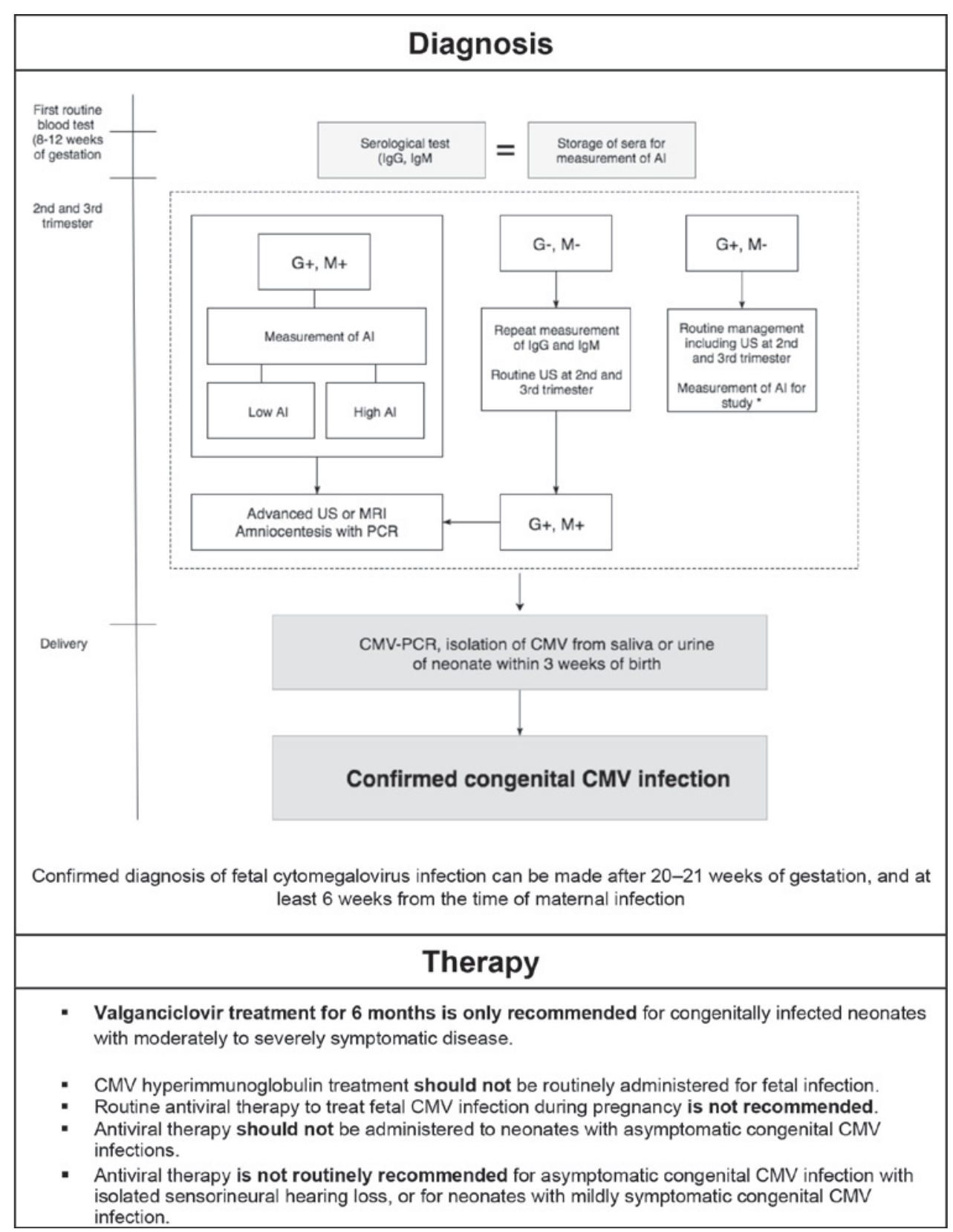

Fig. 2. Flow chart to identify an intrauterine cytomegalovirus-infected infant and recommendations for appropriate treatment (modified from Rawlinson et al, Lancet 2017).

Al, avidity index; ABR, auditory brain stem response; lgG, immunoglobulin G; IgM, immunoglobulin M; US, ultrasonography.

*When Als were measured, maternal sera collected at first trimester were used

should be administered in a protected environment by an appropriate vehicle leading itself to the target cell.

Two basic types of approaches have been proposed: the introduction of protective genes and the activation of transdifferentiation genes. Many investigations have recently shown the success of transfection and expression of neurotrophic factors in the inner ear by viral and non-viral vectors administered through cochlear implants. Neurotrophic factors play a crucial role in differentiation, proliferation, development, neuronal plasticity and cell survival in embryonic development and throughout life. About 20 neurotrophic factors have been studied; among these, the neurotrophin family (NT-3 and 7), glial growth factor (GDNF glial cell linederived neurotrophic factor), brain (brain-derived neurotrophic factor BDNF), platelet (platelet-derived growth factor PDGF) and insulin neurotrophic factors [(IGF, insulin-like growth factor (IGF)] have been extensively studied in improving spiral ganglion neurons survival after cochlear implantation ${ }^{8384}$.

The success of gene therapy depends on the carrier of the gene and both viral or non-viral carriers have been used. Adenovirus 45 , Adeno-associated viruses ${ }^{6-8}$, Lentivirus ${ }^{9}$, type 1 Herpes simplex virus and Vaccinia virus 1011 have all shown promising results. However, their use is coupled with a high potential for toxicity, immunogenicity and/ or mutagenicity. Non-viral vectors are safer and offer greater possibilities for manipulation and more flexibility for the transfected gene size; among these, the most important candidates as carriers are nanoparticles and nanolipidic-capsules that could be applied to the round window. However, their poor nuclear localisation in cochlear cells limits their application in gene therapy. Although gene therapy is a promising treatment option, its application is currently limited by the risk of side effects and is still under study to ensure that it will be safe and effective.

\section{Stem cells}

Transplantation of progenitor cells capable of differentiation into functional hair and/or spiral ganglion cells is undoubtedly a fascinating strategy. Embryonic, foetal, cord blood, central nervous system, placental stem cells or adult cells of the inner ear have been shown to differentiate into cells such as hair cells with mechano-sensitive functioning 
cilia in vitro ${ }^{85}$. More recently, Koehler et al. have published the generation in 3D culture of functioning inner ear sensory epithelia from pluripotent stem cells; they reported that these stem-cell-derived hair cells exhibit functional properties of native mechanosensitive hair cells and form specialised synapses with sensory neurons that have also arisen from mouse embryonic stem cells in the culture ${ }^{86}$.

Several laboratories have begun to study the implantation of these cells in models of deafness. At present, only limited survival has been shown for implanted cells in vivo; in rare cases, these cells became host integrated. Despite much evidence for differentiation into mature cell types, there has been no clear demonstration that hair cells can have functional recovery ${ }^{87}$. However, it remains to be accurately determined if stem cells can differentiate into hair cells or rather, more likely, they can promote reparative and trophic effects on sensorineural epithelia, stria vascularis and spiral ganglion neurons, limiting the regenerative effects on the supporting cells ${ }^{158788}$.

\section{Conclusions}

Although considerable progresses have been made in recent years, pathways for hearing preservation and restoration in children are still controversial. The progressively increasing knowledge about the pathophysiological mechanisms underlying cell death and reparation, inner ear genetics and development of new technologies to deliver therapies into a specific target represents a solid basis for research in this field.

The literature shows more than 110 molecules proposed to date in the prevention or repair of cochlear damage by exogenous factors; however, for most of these drugs, their use is not supported by clinical data. Corticosteroids represent a milestone for treatment of SNHL in children, even if there are no guidelines or indications for their use in children. Antiviral therapy for CMV infection may reduce the incidence of the most common cause of acquired sensorineural hearing loss, while research for a CMV vaccine is continues to be challenging. The possibility of combining nanotechnologies with cochlear implants for the application of targeted molecules or gene is probably the most attractive perspective for the near future. Finally, the role of stem cells in the inner ear is still debated, as they appear to be more involved in the reparative processes rather than differentiating into functioning hair cells.

\section{References}

1 Kral A, O'Donoghue GM. Profound deafness in childhood. N Engl J Med 2010;363:1438-50.

2 Prosser JD, Cohen AP, Greinwald JH. Diagnostic evaluation of children with sensorineural hearing loss. Otolaryngol Clin North Am 2015;48:975-82.
3 Iseli C, Buchman CA. Management of children with severe, severe-profound, and profound sensorineural hearing loss. Otolaryngol Clin North Am 2015;48:995-1010.

4 Bass JK, Bhagat SP. Challenges in ototoxicity monitoring in the pediatric oncology population. J Am Acad Audiol 2014;25:760-74.

5 Smith RJ, Bale JF Jr, White KR. Sensorineural HL in children. Lancet 2005;365:879-90.

6 Elziere M, Roman S, Nicollas R, et al. Value of systematic aetiological investigation in children with sensorineural hearing loss. Eur Ann Otorhinolaryngol Head Neck Dis 2012;129:185-9.

7 Fetoni AR, Ralli M, Sergi B, et al. Protective effects of $N$ acetylcysteine on noise-induced HL in guinea pigs. Acta Otorhinolaryngol Ital 2009;29:70-5.

8 Carey JC, Palumbos JC. Advances in the understanding of the genetic causes of HL in children inform a rational approach to evaluation. Indian J Pediatr 2016;83:1150-6.

9 Xia W, Liu F, Ma D. Research progress in pathogenic genes of hereditary non-syndromic mid-frequency deafness. Front Med 2016;10:137-42.

10 Spracklen TF, Vorster AA, Ramma L, et al. Promoter region variation in NFE2L2 influences susceptibility to ototoxicity in patients exposed to high cumulative doses of cisplatin. Pharmacogenomics J 2016; doi:10.1038/tpj.2016.52.

11 Rainey RN, Ng SY, Llamas J, et al. Mutations in Cockayne syndrome-associated genes (Csa and Csb) predispose to cisplatin-induced HL in mice. J Neurosci 2016;36:4758-70.

12 Brown AL, Lupo PJ, Okcu MF, et al. SOD2 genetic variant associated with treatment-related ototoxicity in cisplatin-treated pediatric medulloblastoma. Cancer Med 2015;4:1679-86.

13 Brock PR, Knight KR, Freyer DR, et al. Platinum-induced ototoxicity in children: a consensus review on mechanisms, predisposition, and protection, including a new International Society of Pediatric Oncology Boston ototoxicity scale. J Clin Oncol 2012;30:2408-17.

14 Fetoni AR, Ruggiero A, Lucidi D, et al. Audiological monitoring in children treated with platinum chemotherapy. Audiol Neurootol 2016;21:203-11.

15 Brigande JV, Heller S. Quo vadis, hair cell regeneration? Nat Neurosci 2009;12:679-85.

16 Abi-Hachem RN, Zine A, Van De Water TR. The injured cochlea as a target for inflammatory processes, initiation of cell death pathways and application of related otoprotectives strategies. Recent Pat CNS Drug Discov 2010;5:147-63.

17 Keithley EM, Wang X, Barkdull GC. Tumor necrosis factor alpha can induce recruitment of inflammatory cells to the cochlea. Otol Neurotol 2008;29:854-9.

18 Dinh CT, Haake S, Chen S, et al. Dexamethasone protects organ of corti explants against tumor necrosis factor-alpha-induced loss of auditory hair cells and alters the expression levels of apoptosis-related genes. Neuroscience 2008;157:405-13.

19 Lawrence R, Thevasagayam R. Controversies in the management of sudden sensorineural hearing loss: an evidencebased review. Clin Otolaryngol 2015;40:176-82.

20 Wei BP, Stathopoulos D, O'Leary S. Steroids for idiopathic sudden sensorineural hearing loss. Cochrane Database Syst Rev 2013;(7):CD003998.

${ }^{21} \mathrm{Ng} \mathrm{JH}$, Ho RC, Cheong CS, et al. Intratympanic steroids as 
a salvage treatment for sudden sensorineural hearing loss? A meta-analysis. Eur Arch Otorhinolaryngol 2015;272:2777-82.

22 Bear ZW, Mikulec AA. Intratympanic steroid therapy for treatment of idiopathic sudden sensorineural hearing loss. Mo Med 2014;111:352-6.

23 Eshraghi AA, Lang DM, Roell J, et al. Mechanisms of programmed cell death signaling in hair cells and support cells postelectrode insertion trauma. Acta Otolaryngol 2015;135:328-34.

24 Eastwood H, Chang A, Kel G, et al. Round window delivery of dexamethasone ameliorates local and remote HL produced by cochlear implantation into the second turn of the guinea pig cochlea. Hear Res 2010;265:25-9.

25 Vivero RJ, Joseph DE, Angeli S, et al. Dexamethasone base conserves hearing from electrode trauma-induced hearing loss. Laryngoscope 2008;118:2028-35.

26 Maini S, Lisnichuk H, Eastwood H, et al. Targeted therapy of the inner ear. Audiol Neurootol 2009;14:402-10.

27 Paasche G, Bockel F, Tasche C, et al. Changes of postoperative impedances in cochlear implant patients: the short-term effects of modified electrode surfaces and intracochlear corticosteroids. Otol Neurotol 2006;27:639-47.

28 Ye Q, Tillein J, Hartmann R, et al. Application of a corticosteroid (Triamcinolon) protects inner ear function after surgical intervention. Ear Hear 2007;28:361-9.

29 Paasche G, Tasche C, Stöver T, et al. The long-term effects of modified electrode surfaces and intracochlear corticosteroids on postoperative impedances in cochlear implant patients. Otol Neurotol 2009;30:592-8.

30 Rah YC, Lee MY, Kim SH, et al. Extended use of systemic steroid is beneficial in preserving hearing in guinea pigs after cochlear implant. Acta Otolaryngol 2016;136:1213-9.

31 Worsøe L, Brandt CT, Lund SP, et al. Intratympanic steroid prevents long-term spiral ganglion neuron loss in experimental meningitis. Otol Neurotol 2010;31:394-403.

32 Molyneux EM, Walsh AL, Forsyth H, et al. Dexamethasone treatment in childhood bacterial meningitis in Malawi: a randomised controlled trial. Lancet 2002;360:211-8.

33 Brouwer MC, Tunkel AR, van de Beek D. Epidemiology, diagnosis, and antimicrobial treatment of acute bacterial meningitis. Clin Microbiol Rev 2010;23:467-92.

34 Brouwer MC, McIntyre P, Prasad K, et al. Corticosteroids for acute bacterial meningitis. Cochrane Database Syst Rev 2015:CD004405.

35 Herson VC, Todd JK. Prediction of morbidity in Hemophilusinfluenzae meningitis. Pediatrics 1977;59:35-9.

36 Kilpi T, Peltola H, Jauhiainen T, et al. Oral glycerol and intravenous dexamethasone in preventing neurologic and audiologic sequelae of childhood bacterial meningitis. The Finnish Study Group. Pediatr Infect Dis J 1995;14:270-8.

37 Peltola H, Roine I, Fernández J, et al. Hearing impairment in childhood bacterial meningitis is little relieved by dexamethasone or glycerol. Pediatrics 2010;125:e1-8.

38 Azzopardi D. Hypoxic ischaemic encephalopathy in newborn infants. Early Hum Dev 2010;86:327.

39 Perrone S, Szabó M, Bellieni CV, et al. Whole body hypothermia and oxidative stress in babies with hypoxic-ischemic brain injury. Pediatr Neurol 2010;43:236-40.

40 Fetoni $\mathrm{AR}$, Mancuso $\mathrm{C}$, Eramo SL, et al. In vivo protective effect of ferulic acid against noise-induced HL in the guineapig. Neuroscience 2010;169:1575-88.

${ }^{41}$ Fetoni AR, Piacentini R, Fiorita A, et al. Water-soluble Coenzyme Q10 formulation (Q-ter) promotes outer hair cell survival in a guinea pig model of noise induced $H L(N I H L)$. Brain Res 2009;1257:108-16.

42 Fetoni AR, Troiani D, Eramo SL, et al. Efficacy of different routes of administration for Coenzyme Q10 formulation in noise-induced hearing loss: systemic versus transtympanic modality. Acta Otolaryngol 2012;132:391-9

43 Fetoni AR, Eramo SL, Rolesi R, et al. Antioxidant treatment with coenzyme $Q$-ter in prevention of gentamycin ototoxicity in an animal model. Acta Otorhinolaryngol Ital 2012;32:103-10.

44 Fetoni AR, Garzaro M, Ralli M, et al. The monitoring role of otoacoustic emissions and oxidative stress markers in the protective effects of antioxidant administration in noise-exposed subjects: a pilot study. Med Sci Monit 2009;15:PR1-8.

45 Poirrier AL, Van den Ackerveken P, Kim TS, et al. Ototoxic drugs: difference in sensitivity between mice and guinea pigs. Toxicol Lett 2010;193:41-9.

46 Gilles A, Ihtijarevic B, Wouters K, et al. Using prophylactic antioxidants to prevent noise-induced hearing damage in young adults: a protocol for a double-blind, randomized controlled trial. Trials 2014;15:110.

47 Sheppard A, Hayes SH, Chen GD, et al. Review of salicylateinduced hearing loss, neurotoxicity, tinnitus and neuropathophysiology. Acta Otorhinolaryngol Ital 2014;34:79-93.

48 Sha SH, Schacht J. Salicylate attenuates gentamicin-induced ototoxicity. Lab Invest 1999;79:807-13.

$49 \mathrm{Li} \mathrm{G}$, Sha SH, Zotova E, et al. Salicylate protects hearing and kidney function from cisplatin toxicity without compromising its oncolytic action. Lab Invest 2002;82:585-96.

${ }^{50}$ Chen Y, Huang WG, Zha DJ, et al. Aspirin attenuates gentamicin ototoxicity: from the laboratory to the clinic. Hear Res 2007;226:178-82.

51 Chen GD, Kermany MH, D'Elia A, et al. Too much of a good thing: long-term treatment with salicylate strengthens outer hair cell function but impairs auditory neural activity. Hear Res 2010;265:63-9.

52 Ralli M, Lobarinas E, Fetoni AR, et al. Comparison of salicylate- and quinine-induced tinnitus in rats: development, time course, and evaluation of audiologic correlates. OtolNeurotol 2010;31:823-31.

53 Ralli M, Troiani D, Podda MV, et al. The effect of the NMDA channel blocker memantine on salicylate-induced tinnitus in rats. Acta Otorhinolaryngol Ital 2014;34:198-204.

54 Dickey DT, Wu YJ, Muldoon LL, et al. Protection against cisplatin-induced toxicities by $\mathrm{N}$-acetylcysteine and sodium thiosulfate as assessed at the molecular, cellular, and in vivo levels. J Pharmacol Exp Ther 2005;314:1052-8.

55 Wang J, Lloyd Faulconbridge RV, Fetoni A, et al. Local application of sodium thiosulfate prevents cisplatin-induced HLin the guinea pig. Neuropharmacology 2003;45:380-93.

56 Harned TM, Kalous O, Neuwelt A, et al. Sodium thiosulfate administered six hours after cisplatin does not compromise antineuroblastoma activity. Clin Cancer Res 2008;14:533-40.

57 Neuwelt EA, Gilmer-Knight K, Lacy C et al. Toxicity profile of delayed high dose sodium thiosulfate in children treated 
with carboplatin in conjunction with blood-brain-barrier disruption. Pediatr Blood Cancer 2006;47:174-82.

${ }^{58}$ Gurney JG, Bass JK, Onar-Thomas A, et al. Evaluation of amifostine for protection against cisplatin-induced serious $H L$ in children treated for average-risk or high-risk medulloblastoma. Neuro Oncol 2014;16:848-55.

59 Fouladi M, Chintagumpala M, Ashley D, et al. Amifostine protects against cisplatin-induced ototoxicity in children with average-risk medulloblastoma. J Clin Oncol 2008;26:3749-55.

${ }^{60}$ Marina N, Chang KW, Malogolowkin M, et al. Children's Oncology Group. Amifostine does not protect against the ototoxicity of high-dose cisplatin combined with etoposide and bleomycin in pediatric germ-cell tumors: a Children's Oncology Group study. Cancer 2005;104:841-7.

${ }_{61}$ Ozkul Y, Songu M, Basoglu MS, et al. Evaluation of the protective effect of a-lipoic acid on cisplatin ototoxicity using distortion-product otoacoustic emission measurements: an experimental animal study. J Craniofac Surg 2014;25:1515-8.

62 Huang J, Wang P, Li M et al. Trichostatin A reduces cisplatin-induced ototoxicity through the STAT6 signaling pathway. Int J Mol Med 2015;36:493-500.

63 BekmezBilmez ZE, Aydin S, Şanli A, et al. Oxytocin as a protective agent in cisplatin-induced ototoxicity. Cancer Chemother Pharmacol 2016;77:875-9.

${ }^{64}$ Lee SH, Kim HS, An YS, et al. Protective effect of resveratrol against cisplatin-induced ototoxicity in HEI-OCl auditory cells. Int J Pediatr Otorhinolaryngol 2015;79:58-62.

65 Kara M, Türkön H, Karaca T, et al. Evaluation of the protective effects of hesperetin against cisplatin-induced ototoxicity in a rat animal model. Int J Pediatr Otorhinolaryngol 2016;85:12-8.

66 Roldán-Fidalgo A, Martín Saldaña S, Trinidad A, et al. In vitro and in vivo effects of lutein against cisplatin-induced ototoxicity. ExpToxicol Pathol 2016;68:197-204.

67 Fetoni AR, Paciello F, Mezzogori D, et al. Molecular targets for anticancer redox chemotherapy and cisplatin-induced ototoxicity: the role of curcumin on pSTAT3 and Nrf-2 signalling. Br J Cancer 2015;113:1434-44.

68 James SH, Kimberlin DW. Advances in the prevention and treatment of congenital cytomegalovirus infection. Curr Opin Pediatr 2016;28:81-5.

69 Kimberlin DW, Jester PM, Sánchez PJ, et al. Valganciclovir for symptomatic congenital cytomegalovirus disease. $\mathrm{N}$ Engl J Med 2015;372:933-43.

70 Boeckh M, Murphy WJ, Peggs KS. Recent advances in cytomegalovirus: an update on pharmacologic and cellular therapies. Biol Blood Marrow Transplant 2015;21:24-9.

71 Stockmann C, Roberts JK, Knackstedt ED, et al. Clinical pharmacokinetics and pharmacodynamics of ganciclovir and valganciclovir in children with cytomegalovirus infection. Expert Opin Drug MetabToxicol 2015;11:205-19.

72 Marshall BC, Koch WC. Antivirals for cytomegalovirus infection in neonates and infants: focus on pharmacokinetics, formulations, dosing, and adverse events. Paediatr Drugs 2009;11:309-21.

73 Vora SB, Englund JA. Cytomegalovirus in immunocompromised children. Curr Opin Infect Dis 2015;28:323-9.

74 Gunkel J, Wolfs TF, de Vries LS, et al. Predictors of severity for postnatal cytomegalovirus infection in preterm infants and implications for treatment. Expert Rev Anti Infect Ther 2014;12:1345-55.

75 Dioverti MV, Lahr B, Razonable RR. Treatment of cytomegalovirus infection and disease pre- and post-quantitative nucleic acid test standardization: does use of a more sensitive assay lead to longer treatment duration? Clin Transplant 2016;30:154-60.

76 Shin JJ, Keamy DG Jr, Steinberg EA. Medical and surgical interventions for HL associated with congenital cytomegalovirus: a systematic review. Otolaryngol Head Neck Surg 2011;144:662-75.

77 Rawlinson WD, Boppana SB, Fowler KB, et al. Congenital cytomegalovirus infection in pregnancy and the neonate: consensus recommendations for prevention, diagnosis, and therapy. Lancet Infect Dis 2017;17:e177-e188.

78 Pyykkö I, Zou J, Schrott-Fischer A, et al. An overview of nanoparticle based delivery for treatment of inner ear disorders. Methods Mol Biol 2016;1427:363-415.

79 Zou J, Saulnier P, Perrier T, et al. Distribution of lipid nanocapsules in different cochlear cell populations after round window membrane permeation. J Biomed Mater Res B Appl Biomater 2008;87:10-8.

80 Roy S, Johnston AH, Newman TA, et al. Cell-specific targeting in the mouse inner ear using nanoparticles conjugated with a neurotrophin-derived peptide ligand: potential tool for drug delivery. Int J Pharm 2010;390:214-24.

81 Zhang Y, Zhang W, Löbler M, et al. Inner ear biocompatibility of lipid nanocapsules after round window membrane application. Int J Pharm 2011;404:211-9.

82 Mulligan RC. The basic science of gene therapy. Science 1993;260:926-32.

83 Wise AK, Tu T, Atkinson PJ, et al. The effect of deafness duration on neurotrophin gene therapy for spiral ganglion neuron protection. Hear Res 2011;278:69-76.

${ }_{84}$ Taecker H, Garnham C. Neurotrophin therapy and cochlear implantation: translating animal models to human therapy. Exp Neurol 2010;226:1-5.

85 Oshima K, Shin K, Diensthuber M, et al. Mechanosensitive hair cell-like cells from embryonic and induced pluripotent stem cells. Cell 2010;141:704-16.

86 Koehler KR, Mikosz AM, Molosh AI, et al. Generation of inner ear sensory epithelia from pluripotent stem cells in $3 D$ culture. Nature 2013;500:217-21.

87 Santaolalla F, Salvador C, Martínez A, et al. Inner ear hair cell regeneration: A look from the past to the future. Neural Regen Res 2013;8:2284-9.

88 Park YH. Stem cell therapy for sensorineural hearing loss, still alive? J Audiol Otol 2015;19:63-7. 